\title{
NOTES ON THREE ABNORMAL ANTS ${ }^{1}$.
}

\author{
By W. S. Creighton
}

Abnormalities in ants appear to fall into three fairly well
defined categories, viz.: (1) sex mosaics and intersexes, (2) aberrant forms produced through altered food supply, (3) freaks. To the first group belong the various kinds of lateral mosaics as well as the rarer anterio-posterior type. The latter often show characteristics which mark them as intersexes rather than true mosaics. The second group is composed of a large number of peculiar forms which arise from pronounced nutritional irregularities. Lack of food may produce dwarf individuals in all three castes, while loss of food due to the presence of parasites gives rise to pseudogynes or the shriveled victims of Orasema. In the event of an overabundance of food unusually large males and females, egg-laying workers and, more rarely, repletes may result. It is impossible to draw any hard and fast line between the members of this group and those forms considered normal since in many cases conditions which originally must have been quite aberrant have, in time, become an integral part of the life of the species (e. g. the repletes of Myrmecocystus or the microgynes of certain Formicas). In the third group may be included those individuals which show duplication, loss or malformation of parts. Most of these conditions seem to be due to injuries in the larval or pupal stages. More rarely the changes are of an atavistic nature. Many of the members of this group are veritable entomological nightmares, monstrosities with double scapes or legs; fantastic creatures with shortened and twisted antennæ and limbs or misshappen thoraces; freaks without eyes, or lacking tarsal, antennal, rarely even petiolar joints.

In this paper are described three abnormal ants, two freaks and an ergatandromorph. Both freaks are in the collection of Dr. Wheeler through whose kindness I am enabled to describe them. It is therefore my pleasure to thank the donors for their

${ }^{1}$ Contributions from the Entomological Laboratory of the Bussey Institution, Harvard University, No. 291. 
contributions. The first of these, a queen of Monomorium minimum Em. which lacks the left eye, was taken at Urbana, Ill. by Mr. M. R. Smith. Plate. 1, Fig. 4 shows the head of the insect. The asymetry caused by the absence of the left eye is further increased by a narrowing of the same side of the head. The left half is very little more than half the width of the right except just behind the mandible where it suddenly flares out to full width. The left ocellus is misshappen and displaced. Dr. P. W. Whiting informs me that similarly deficient individuals occasionally arise in his Habrobracon stocks, and when, as more rarely happens, both eyes are absent, extreme microcephaly results. No dissection was made of the insect here described but it seems likely that the greater portion of the left optic tract is absent. The cross sectional area of the mandibular muscles must also be greatly reduced. In all other regards the specimen appears to be perfectly normal.

The second abnormality is a dealated queen of Myrmica scabrinodis var. (probably sabuleti Mein.) which lacks both petiole and post petiole. This astonishing insect was found by Miss H. Andrews at Boulder, Colo. in 1916. Figs. 5 and 6 show the thorax and abdomen in profile and from above. The thorax is joined directly to the gaster, the two petiolar joints having fused with the anterior face of the first gastric segment. The joints are broadened and flattened past recognition, forming a fan-shaped area on the gaster. Nevertheless their nature is strikingly apparent because of their characteristic rugose sculpture and lighter color. On the right side of the gaster close to the fused nodes is a small tubercle. It has no apparent connection with them nor any obvious significance. At least two similar abnormalities have been previously described. Donisthorpe, in 1922, published a short paper containing an account of a dealated queen of Leptothorax acervorum $\mathrm{F}$. which lacks the petiolar joints. The altered condition of this insect he considers an atavism. In 1927 Karajew described an aberrant worker of Megaponera fatens F. in which the petiole is absent. Unfortunately the insect was not figured but the author notes that in other respects it was normal.

The last specimen to be dealt with in this paper is an ergat- 
andromorph which I took in the summer of 1927 at Boulder, Colorado. On August 10th while collecting along the foot of the ridge between Gregory and Bluebell Canyons, I found a nest of Formica nitidiventris, Em. containing an ant with wings on the left side only. The insect was in the upper galleries of the nest in the company of twenty or thirty workers. The latter fled as soon as the covering stone was raised, leaving the ergatandromorph whose slower movements hindered its escape. When allowed to walk on a relatively smooth surface it circled to the right.

Fig. 1 shows the more important features. The left half of the insect is male, the right worker, although in the head and thorax the junction does not occur at the mid-line of the body. The structures of the opposite sides of the head appear to be quite typical as regards their respective castes. The right (worker) antenna has the requisite twelve joints of the customary shape and size. The right eye and mandible differ in no way from those of the normal worker. On the left (male) side the eye is much larger, the mandible greatly reduced and the antenna of thirteen joints, all usual male features. The clypeus is twisted to the left, a result of the obvious discrepancy in the length of the genæ (Fig. 2.) Aside from the major structural differences in the males and workers of this subspecies there are certain pecularities of color and pilosity characteristic of each. Thus the head and thorax of the normal worker are a rufous brown and those of the male a deep brownish black. In Figs. 1 and 2 this darker male coloration has been indicated by stippling. Referring to 2 it may be seen that the entire clypeus and most of the vertex and occiput are of worker origin. There is also a curious projection of worker tissue which runs downward from the vertex to the upper border of the eye. All three ocelli occur in worker tissue and all are of the small size characteristic of the worker.

Taking into consideration the radical differences in the thoracic structured of the male and worker the thorax of the mosaic is less mixed than would appear at first sight. The prothorax of the worker has fused fairly evenly with the pronotum of the male. The mesothorax is united with the scutum, the 
parapsis and the scutellum. The small metanotum of the male is apparently free throughout the greater part of its length. It lies in a deep suture which extends entirely across the thorax. The last portion of the thorax appears to be intermediate in structure between the metathorax of the worker and the epinotum of the male. Its color would indicate worker tissue but its structure is not that of the typical worker metathorax. Both wings are present on the left side of the insect and both are fully developed. The petiole is cleanly divided along the midline of the body. The right half is higher and broader than the left and has an acute upper edge. The upper edge of the left half is obtuse and the coloration is a blackish brown.

The differences in the shape of the opposite halves of the abdominal segments cause a pronounced asymetry of the gaster. Since the gastric segments of the normal male are of nearly uniform length throughout, while those of the worker successively decrease in length after the second segment, their combination has resulted in a strong bending of the tip of the gaster towards the right. This bending has affected the male genital armature. All the elements in the left half of the male genetalia are present and individually quite normal ${ }^{2}$. Their relative positions, however, have been somewhat altered. In the normal male the stipites are outermost in position. Just within and closely appressed to each of these is a bifurcate organ composed of an outer, hooked volcella and an inner, foliate lacinia. Innermost of all and somewhat above the rest are the paired inner paramera. In addition there are present two small lobed structures, the cerci. Ordinarily these lie just above the median lobes and are partially covered by the sixth gastric segment. They are apparently not a part of the genetalia and are mentioned here only because a single aberrant cercus occurs in the gynandromorph. Fig. 3. shows the position of the male genital armature in the mosaic. The stipes ( $\mathrm{s}$ ) has been turned inward toward the center so that it occupies a position above the volcella (v) and

2Emery's nomenclature is here used. For a discussion of the names applied to the structures of the Formicid genetalia see Emery, Die Gattung Dorylus. Mol. Jahrb Band 81895. 
lacinia (l) and the inner paramer (p). The ends of these may be seen projecting to the right of the stipes.

Above the stipes is the sixth gastric segment of the male. Near the base of the stipes is the small, club-shaped cercus (c). It is entirely exposed and borne on a small extruded portion of unchitinized tissue. The very characteristic circular, hair-fringed anal aperture of the worker, if present, is distorted past recognition.

The legs of the two halves of the mosaic are normal for male and worker respectively. Those of the male side are darker and somewhat more curved than their opposites. Measurements show them to be slightly shorter. The figure cannot be used in this connection since no attempt was made to draw opposite appendages in similar positions. The difference in length is such that one would expect the insect to circle gradually to the left when walking. Actually, as has been noted, it circled sharply to the right, a result probably due to the distortion of muscles in the thorax.

\section{Literature Cited.}

Donisthorpe, H. 1922. On some Abnormalities in Ants. The Entomologists Record, Vol. XXXIV., No. 5.

Karawajew, W. 1927. Ein Fall von lateralem Hemaphroditismus bei Ameisen und ein Fall defekter Körperbildung. Folia Myrmecologica et Termitologica Vol. I Nr. 4-5. 

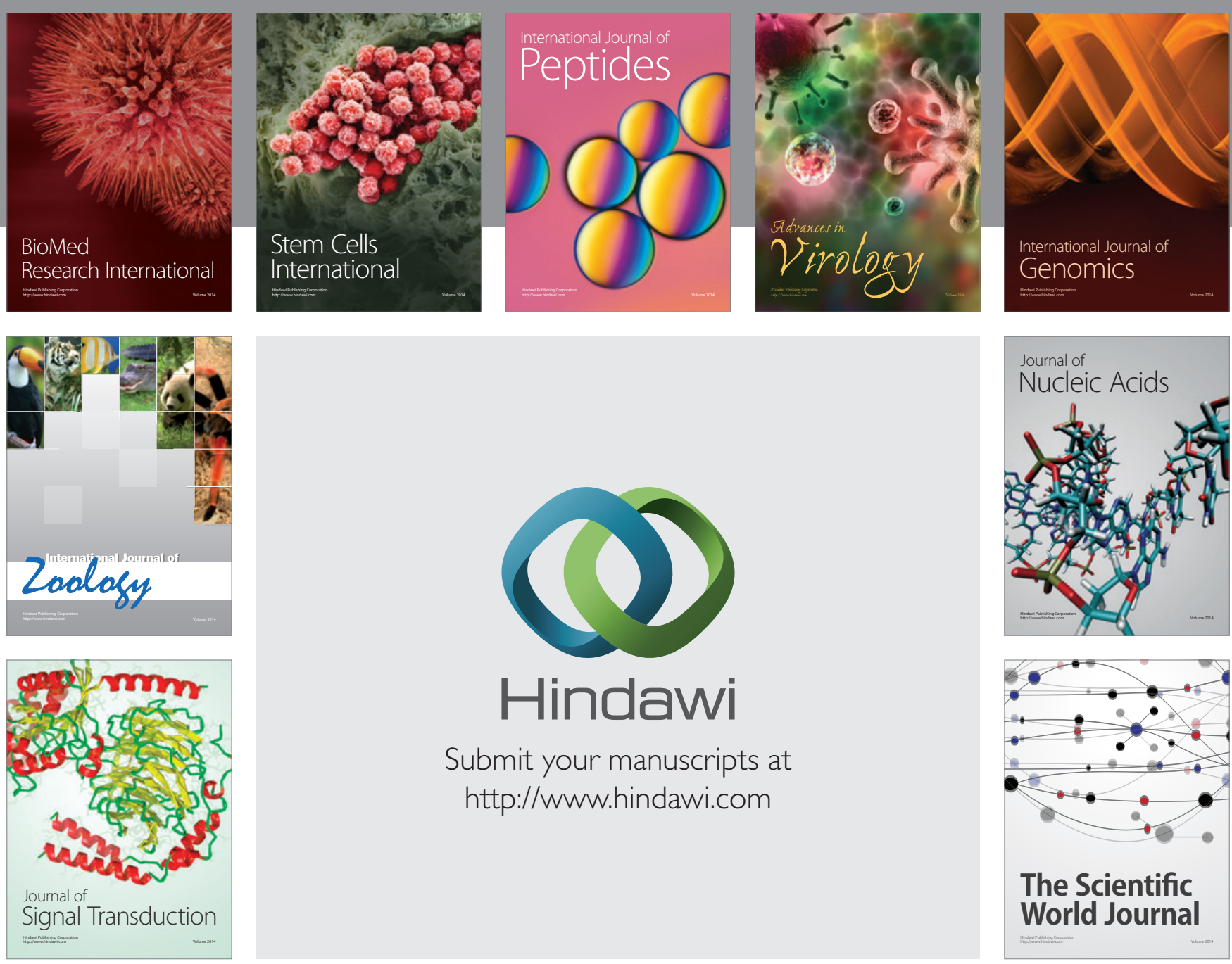

Submit your manuscripts at

http://www.hindawi.com
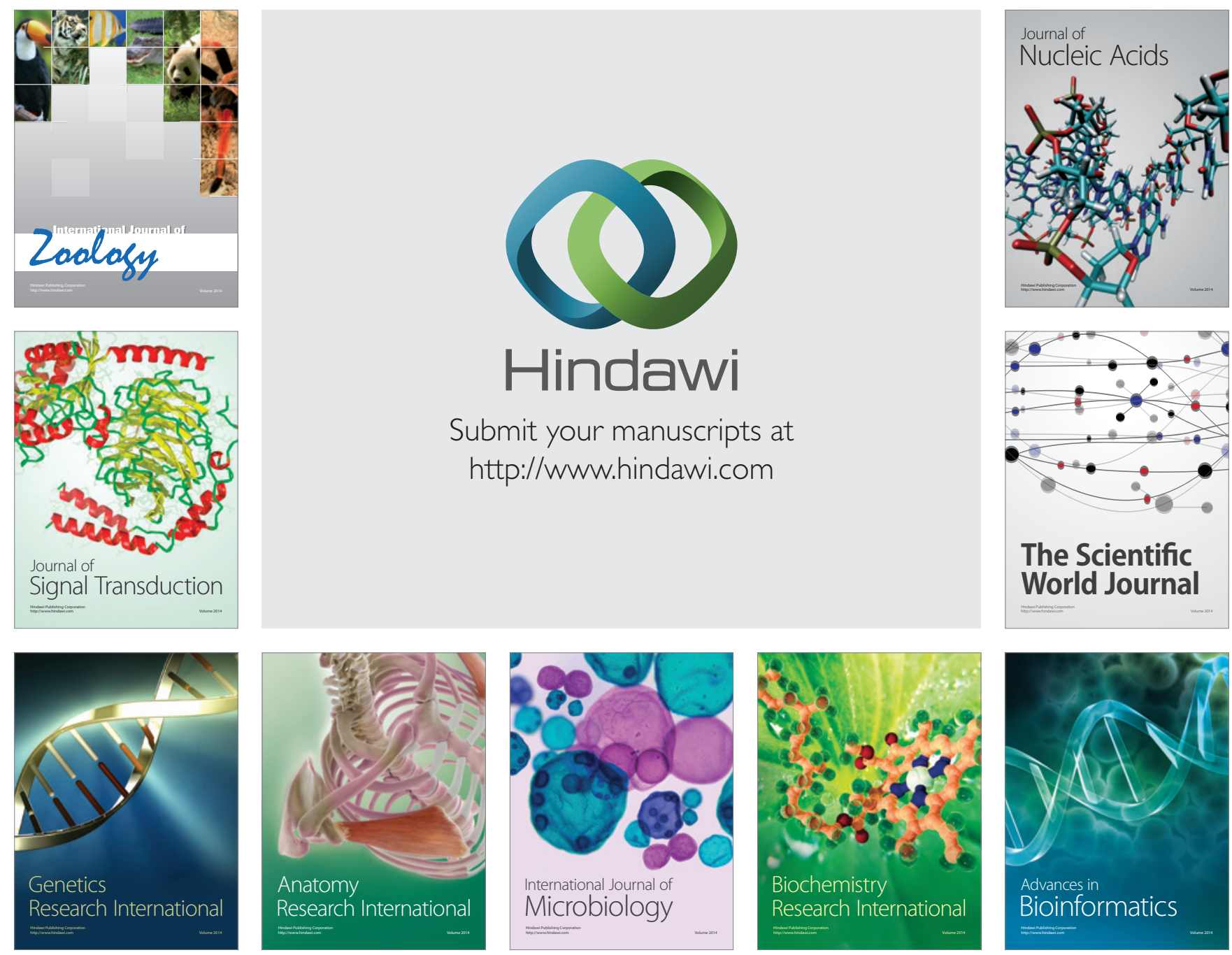

The Scientific World Journal
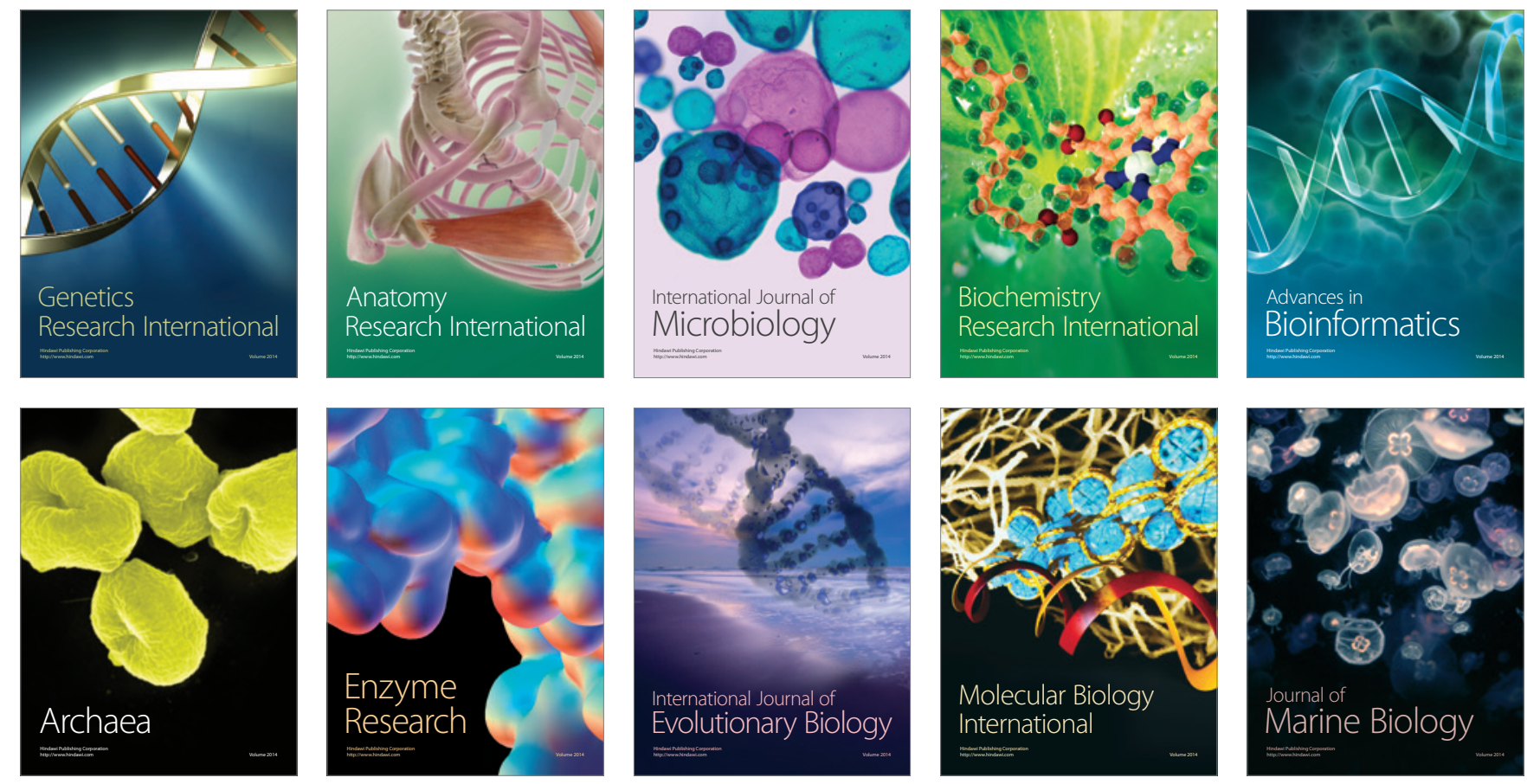